bubbles, about twice the thickness of the blue bands. The blue bands are irregular and sometimes anastomose. This system is similar to the veined structure found higher up the glacier.

The second system is formed by large and regular blue bands from three to six inches broad and from two to six or more feet apart. This coarser system is only occasionally developed. The finer system forms a well-marked synclinal curve on the terminal ice cliffs, which are from 250 to 3 co feet high.

The ice here contains in places numerous angular stones, principally of slate, scattered irregularly through it, and these fragments always have their broad, or cleaved, surfaces parallel to the smaller system of veins. These stones have no doubt entered the ice through the numerous moulins and crevasses which are found higher up the glacier, but as they are not found in bands nor in pipes, they must have been moved in position by the flowing of the ice, consequently they must originally have been variously oriented, and their present parallelism to the veins is a decisive proof that the smaller system is due to pressure at right angles to the structure. The origin of the coarser system is not so clear. I did not notice it higher up the glacier, as I ought to have done if it had been an older system than the smaller veins. While, on the other hand, if it is a newer system the rock fragments would probably have been oriented parallel with it instead of with the finer system.

The clear blue ice is generally supposed to resist melting better than the white ice, and to stand out in ridges; but observed nothing of this on the Mueller Glacier. Both kinds of ice melt here with about equal rapidity. The grooving. of the ice, by runlets of water, is certainly parallel to the structure when that structure is vertical or highly inclined; but the grooves are formed in several layers of both kinds of ice, and it seemed to me that the blue ice melted rather more rapidly than the white ice. I cannot suggest any cause for this difference between the ice of the Mueller Glacier and that of the Swiss glaciers.

Christchurch, New Zealand, March 22. F. W. Hutron.

\section{On the Rainfall and Temperature at Victoria Peak, Hong Kong.}

THE first column of the following table shows the month of the year; the second, the mean rainfall at the Observatory (about 100 feet above the sea) from ten years' records; the third, the mean of the past four years' fall; the fourth, same for Victoria Peak (about I80o feet above the sea); the fifth, the proportion between the figures in the two preceding columns; the sixth, the height of ascent in feet for one Fahrenheit degree of decrease of temperature (mean of the past four years) :-

\begin{tabular}{|c|c|c|c|}
\hline $\begin{array}{ccc}\text { I. } & \text { II. } \\
\text { January } & \ldots \ldots \ldots \ldots & \text { I } 47\end{array}$ & $\begin{array}{l}\text { III. } \\
2 * 97\end{array}$ & $\begin{array}{l}\text { IV. } \\
4 \cdot 63\end{array}$ & $\begin{array}{l}\text { v. } \\
\text { I. } 56\end{array}$ \\
\hline February $\ldots \ldots \ldots \times 166$ & $2 \cdot 30$ & 3.56 & 1.55 \\
\hline March ….... 3.53 & $3.4 x$ & $3 \cdot 60$ & I.06 \\
\hline April ........... 6.55 & 7.89 & $9 \cdot 19$ & $1 \cdot 16$ \\
\hline May $\ldots \ldots \ldots \ldots . . .692$ & 4.86 & $6 \cdot 29$ & $1 \cdot 29$ \\
\hline June $\ldots \ldots \ldots \ldots \times 2 \cdot 67$ & 14.42 & 16.71 & I.16 \\
\hline July $\ldots \ldots \ldots \ldots 16 \cdot 4 \mathrm{r}$ & $16 \div 55$ & $20 \cdot 29$ & $x \cdot 23$ \\
\hline August ........16.93 & $15 \cdot 27$ & 17.53 & 1.15 \\
\hline September..... $9^{.89}$ & 7.98 & 701 & 0.88 \\
\hline October.......... 5.06 & $2 \cdot 57$ & $2 \cdot 06$ & 0.80 \\
\hline 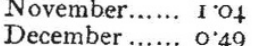 & 0.77 & $\begin{array}{r}x \cdot 9 \\
x \cdot 9\end{array}$ & $\mathrm{I} \cdot 54$ \\
\hline December ...... 0.49 & 0.97 & $1 \cdot 21$ & $1 \cdot 25$ \\
\hline
\end{tabular}

The rainfall at the l'eak exceedis the record at the Observatory by about one-sixth of the whole amount, and this appears to be due to the circumstance that the mountain presents an obstacle to the wind from whatever side it blows, in consequence of which the air is forced to rise, and being thereby cooled it precipitates more moisture in the form of rain. Even when the air is moderately dry at sea-level its temperature may be decreased below the dew-point in the course of such a rise. The comparatively great rainfall in hilly districts must be attributed to this, for a hill must or course exercise its infuence at a distance all round. Our rainfall would therefore be smaller if there were no hills in this neighbourhood. But during the months of September and October less rain is collected at the upper level. This is explained by the circumstance that most of the rain in those months is due to typhoons, when the air is everywhere as- cending, even above the open sea; and the defect at the Peak is most noticeable during the raging of a typhoon. The fact that less rain is measured above must, however, be further investigated. It is very doubtful whether it would not be as well to expose the funnels of the gauges 4 feet above the ground, where they would not be so much affected by the rain drifting along the surface of the earth in typhoons, as to have them I foot above the grass, as is the case here.

The last column of the table proves the great variability of the fall of temperature with increasing height. It depends upon the humidity of the air. The astronomical refraction near the horizon must be affected by this, but it is rather doubtful whether the effect should be ascertained by comparing observed refractions with meteorological registers kept on mountains on account of the condensation of moisture which tends to raise the temperature on the top of the hill. But it would appear to be time that some astronomer studied the refraction in connection with daily weather-maps, seeing that the variation of temperature with increasing height is so different in cyclones and anticyclones. Of course near the centre of a cycione it is scarcely possible to make astronomical observations. Bessel's theory of refraction is considered a failure within $5^{\circ}$ of the horizon. Ivory's theory might possibly be made to account for the refraction nearly down to the horizon by observing the value of the constant $f$ in connection with the isobars. It, on the whole, represents the variation of temperature high up in the air as estimated by meteorologists.

Hong Kong Observatory, February ir.

Problem by Vincentio Viviani.

To pierce in an hemispherical dome four windows such that the remainder of the surface shall be exactly quadrable. It was solved by Leibnitz, J. Bernoulli, and others. Viviani himself, in I692, published the construction, but without proof. Divide the base of the dome into quadrants; on the four radii as diameters trace semi zircles, one in each quadrant; the four right semi-cylinders, of which these are the bases, will pierce the dome in the required windows. The following simple proof, for which I am substantially indebted to Prof. Francis W. Newman, would probably interest many readers of NATURE :-

$O X Y Z$ is quarter of dome; $A B$, generator of cylinder meeting dome in $\mathrm{B} ; \mathrm{ICD}$, plane parallel to base. Radius of dome $=\mathrm{R}=$ $\mathrm{OX}=\mathrm{OB} ;$ angle $\mathrm{CDB}=\mathrm{XOA}=\theta ; \mathrm{DC}=\mathrm{DB}=\mathrm{OA}=\mathrm{R} \cos \theta$ $\mathrm{OB} \cdot \cos \mathrm{BOA}=\mathrm{OA}=\mathrm{R} \cdot \cos \theta ; \therefore \mathrm{BOA}=\theta ; \therefore \operatorname{arc~} \mathrm{EB}=\mathrm{R} \theta$

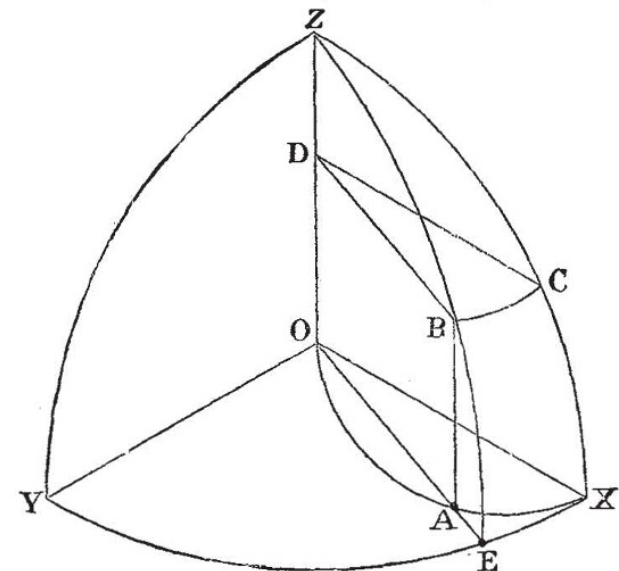

$\operatorname{arc} \mathrm{BC}=\theta . \mathrm{R} \cos \theta$. Element of surface of window is $\mathrm{BC} . d(\mathrm{~EB})$ $=\mathrm{R}^{2} \theta \cdot \cos \cdot \theta \cdot d \theta ; \therefore$ surface of window is the integral of this from $\theta=0$ to $\theta=\frac{1}{2} \pi$. Integrating by parts, and taking limits, surface of window $=\mathrm{R}^{2}\left(\frac{1}{2} \pi-\mathrm{I}\right) ; \therefore$ the remainder of the surface $\mathrm{XYZ}$ is $\mathrm{R}^{2}$, which is exactly quadrable.

Cor. The quadrable part of the quarter-dome is equal to the surface of the semi-cylinder which is within the dome. For, if $\mathrm{AB}=z$, and $\operatorname{arc} \mathrm{XA}=s=\mathrm{R} \theta$, element of surface of the cylinder is $z \cdot d s=\mathrm{R}^{2} \cdot \sin \theta \cdot d \theta ; \therefore$ the entire surface within the dome is the integral of this from $\ddot{\theta}=0$ to $\theta=\frac{1}{2} \pi$, viz. $R^{2}$

A general discussion of Viviani's problém may be seen in Lacroix, "Traité du Calcul Differentiel et du Calcul Intégral," tome ii. pp. 219-22.

Bardsea, May 2. 